\title{
In Situ TEM Observation on Martensitic Transformation during Tensile Deformation of SUS304 Metastable Austenitic Stainless Steel
}

\author{
Xi-Feng Li $\cdot$ Wei Ding $\cdot$ Jian Cao $\cdot$ Li-Yan Ye $\cdot$ Jun Chen
}

Received: 14 April 2014/Revised: 4 July 2014/Published online: 6 January 2015

(c) The Chinese Society for Metals and Springer-Verlag Berlin Heidelberg 2015

\begin{abstract}
Through in situ transmission electron microscopy observation on SUS304 metastable austenitic stainless steel during stretching at room temperature, it is found that $\varepsilon$ martensite plates were induced preferentially from the sites of dislocation pile-ups. With increasing deformation, some of $\varepsilon$ thin martensite platelets disappear and reversibly transform to $\gamma$ austenite without heating treatment, which is different from the previous result that $\varepsilon$ martensite can entirely transform to $\alpha^{\prime}$ martensite. Then, some of deformation twins appear and grow along the vertical direction of $\varepsilon$ martensite due to $(111)_{\gamma} \perp(10 \overline{1} 0)_{\varepsilon}$. Moreover, it is directly observed that multiple transformation mechanisms via $\gamma \rightarrow \varepsilon \rightarrow \gamma, \gamma \rightarrow \varepsilon$, $\gamma \rightarrow \alpha^{\prime}, \gamma \rightarrow \varepsilon \rightarrow \alpha^{\prime}, \gamma \rightarrow$ deformation twins $\rightarrow \alpha^{\prime}$ can co-exist.
\end{abstract}

KEY WORDS: In situ TEM; SUS304 stainless steel; Martensitic transformation; $\varepsilon$ Martensite; Deformation twin

\section{Introduction}

Metastable austenitic stainless steels have been extensively studied for industrial applications due to their combination of superior corrosion resistivity and mechanical properties [1]. Austenite $(\gamma)$ in these stainless steels is unstable and can transform to $\varepsilon$ and $\alpha^{\prime}$ martensite induced by plastic deformation at ambient temperature. $\varepsilon$ martensite nucleates at randomly spaced overlapping stacking faults and $\alpha^{\prime}$ martensite forms at shear band intersections. Generally, the martensitic formation depends on chemical composition,

Available online at http://link.springer.com/journal/40195

X.-F. Li · W. Ding · L.-Y. Ye · J. Chen $(\bowtie)$

Department of Plasticity Technology, School of Materials

Science and Engineering, Shanghai Jiao Tong University,

Shanghai 200030, China

e-mail: jun_chen@sjtu.edu.cn

J. Cao

Department of Mechanical Engineering, Northwestern

University, Evanston, IL 60208-3109, USA temperature, stress state, strain, strain rate and grain size $[2,3]$.

The martensitic transformation mechanisms have been extensively investigated during the past several decades. Olson et al. [4, 5] proposed a general mechanism of martensitic nucleation and found the nucleation sites including grain boundaries, incoherent twin boundaries and inclusion particle interfaces. Das et al. [6, 7] studied the formation and nucleation mechanisms (i.e., $\gamma \rightarrow \varepsilon, \quad \gamma \rightarrow \alpha^{\prime}$, $\gamma \rightarrow$ deformation twins $\rightarrow \varepsilon \rightarrow \alpha^{\prime}$ and $\gamma \rightarrow \varepsilon \rightarrow \alpha^{\prime}$ ) of deformation induced martensite by analytical transmission electron microscopy after tensile deformation in AISI 304LN stainless steel. Bracke et al. [8] investigated the transformation mechanism of $\alpha^{\prime}$ martensite in a Fe-Mn-C$\mathrm{N}$ austenitic alloy and found that $\alpha^{\prime}$-martensite nucleated in the intersection of two $\varepsilon$ martensite laths. Talonen and Hänninen [9] studied the effect of stacking fault energy (SFE) on the formation of shear bands and strain-induced $\alpha^{\prime}$ martensite in austenitic stainless steels. They concluded that the effect of chemical composition, temperature and strain rate on $\alpha^{\prime}$ martensite transformation could have 
mostly resulted from the variation in the SFE. Chen et al. [10] systematically investigated the deformation mechanisms of 304 stainless steel subjected to surface impacts over a wide range of strain rates $\left(10-10^{5} \mathrm{~s}^{-1}\right)$. They proposed the deformation mechanisms via $\gamma \rightarrow$ twin, $\gamma \rightarrow \alpha^{\prime}$, $\gamma \rightarrow \varepsilon$ under high strain rates of $10^{4}-10^{5} \mathrm{~s}^{-1}$, and found that deformation twinning is dominant. On the contrary, dislocation activities and the direct $\gamma \rightarrow \alpha^{\prime}$ transformation are dominant under lower strain rates of $10^{1}-10^{3} \mathrm{~s}^{-1}$.

Actually, a few in situ observation techniques have been used to explore the deformation mechanism of metastable austenitic stainless steel. Fujita and Katayama [11] investigated strain-induced $\gamma \rightarrow \varepsilon \rightarrow \alpha^{\prime}$ and $\gamma \rightarrow \alpha^{\prime}$ martensitic transformations in $\mathrm{Fe}-\mathrm{Cr}-\mathrm{Ni}$ alloys by in situ deformation with a high-voltage electron microscope and verified that both types of transformations resulted from the double shear mechanism. Tao et al. [12] performed in situ neutron diffraction to investigate the martensitic transformation during quasi-static uniaxial compression testing on 304L stainless steel at a cryogenic temperature. Both $\varepsilon$ and $\alpha^{\prime}$ martensites formed at $-70^{\circ} \mathrm{C}$, while no newly formed martensite was detected at $27^{\circ} \mathrm{C}$. Zhang et al. [13] investigated plastic deformation behavior and strain-induced martensitic transformation $\left(\alpha^{\prime}\right)$ in metastable austenitic stainless steel sheets at low strain rate by in situ hydrogen and argon releases and scanning probe microscopy. They also observed the anomalous stress peaks on the stressstrain curve in the later half stage of plastic deformation.

Overall, although the martensitic transformation mechanisms in metastable stainless steel have been intensively studied, multiple transformation mechanisms seem to occur under different conditions. Further study is necessary. Literature on martensitic transformation mechanism studied by in situ TEM has rarely been published. In this study, the martensitic transformation during tensile deformation in SUS304 stainless steel was observed directly by the in situ TEM technique.

\section{Experimental}

Commercial JIS-SUS304 metastable austenitic stainless steel was used in this study. The chemical composition of this steel is listed in Table 1. The material was in strip form with a thickness of $1.2 \mathrm{~mm}$. Specimens were ground with sandpaper and polished with paste. The microstructure was

Table 1 Chemical composition of JIS-SUS304 steel sheet investigated $(\mathrm{wt} \%)$

\begin{tabular}{lllllllll}
\hline $\mathrm{C}$ & $\mathrm{Si}$ & $\mathrm{Mn}$ & $\mathrm{P}$ & $\mathrm{S}$ & $\mathrm{Ni}$ & $\mathrm{Cr}$ & $\mathrm{Al}$ & $\mathrm{Fe}$ \\
\hline 0.07 & 0.47 & 1.94 & 0.028 & 0.001 & 8.29 & 16.59 & 1.05 & $\mathrm{Bal}$. \\
\hline
\end{tabular}

revealed by etching in a 4:3:3 (volume) solution of $\mathrm{H}_{2} \mathrm{O}$, $\mathrm{HCl}$ and $\mathrm{HNO}_{3}$ and observed by an optical microscope.

Three tensile specimens for in situ TEM observation were cut from the as-received SUS304 strips by the wire electrical discharge machine and mechanically ground to a thickness of about $50 \mu \mathrm{m}$ using increasingly finer grades of grit paper. Subsequently, the foils for the tensile holder of TEM were thinned until perforation by twin-jet electropolishing apparatus in a solution of $100 \mathrm{~mL} \mathrm{HClO}_{4}$ and $900 \mathrm{~mL} \mathrm{C}_{2} \mathrm{H}_{5} \mathrm{OH}$ at a voltage of $12 \mathrm{~V}$ and a temperature of $0{ }^{\circ} \mathrm{C}$. Tensile deformation was carried out in a JEM2100 type TEM, equipped with a single tilt tensile specimen holder at $2 \mu \mathrm{m} / \mathrm{s}$ in crosshead speed. In situ TEM observation of tensile samples was operated and recorded at an accelerated voltage of $200 \mathrm{kV}$. The effect of heat input by investigating via electrical guns of TEM is very slight and can be ignored. Thus, this tension was performed at room temperature. A photograph of one in situ TEM tensile specimen and its dimensions are shown in Fig. 1.

\section{Results and Discussion}

The optical micrograph shown in Fig. 2 indicates that the microstructure of as-received SUS304 consists of polygonal grains of austenite with annealing twins, which are characteristic of austenitic stainless steels, interspersed in some grains. The SFE plays an important role in determining the austenite stability. Equation (1) for calculating SFE has been proposed by Schramm and Reed [14]. The corresponding SFE (in $\mathrm{mJ} / \mathrm{m}^{2}$ ) of SUS304 can be calculated by

$$
\begin{aligned}
\mathrm{SFE}= & -53+6.2 \times C_{\mathrm{Ni}}+0.7 \times C_{\mathrm{Cr}} \\
& +3.2 \times C_{\mathrm{Mn}}+9.3 \times C_{\mathrm{Mo}}
\end{aligned}
$$

where $C_{\mathrm{Ni}}, C_{\mathrm{Cr}}, C_{\mathrm{Mn}}$ and $C_{\mathrm{Mo}}$ are the content (in wt $\%$ ) values of $\mathrm{Ni}, \mathrm{Cr}, \mathrm{Mn}$ and $\mathrm{Mo}$, respectively. According to

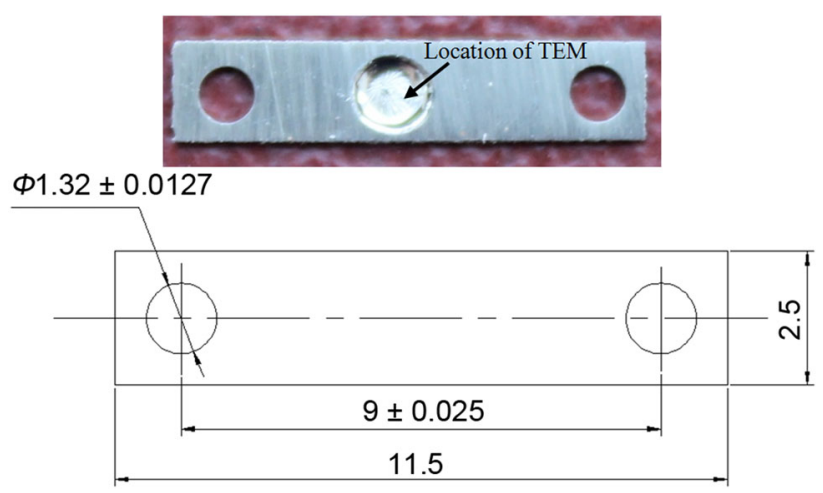

Fig. 1 In situ TEM tensile specimen and its geometry (unit: $\mathrm{mm}$ ) 


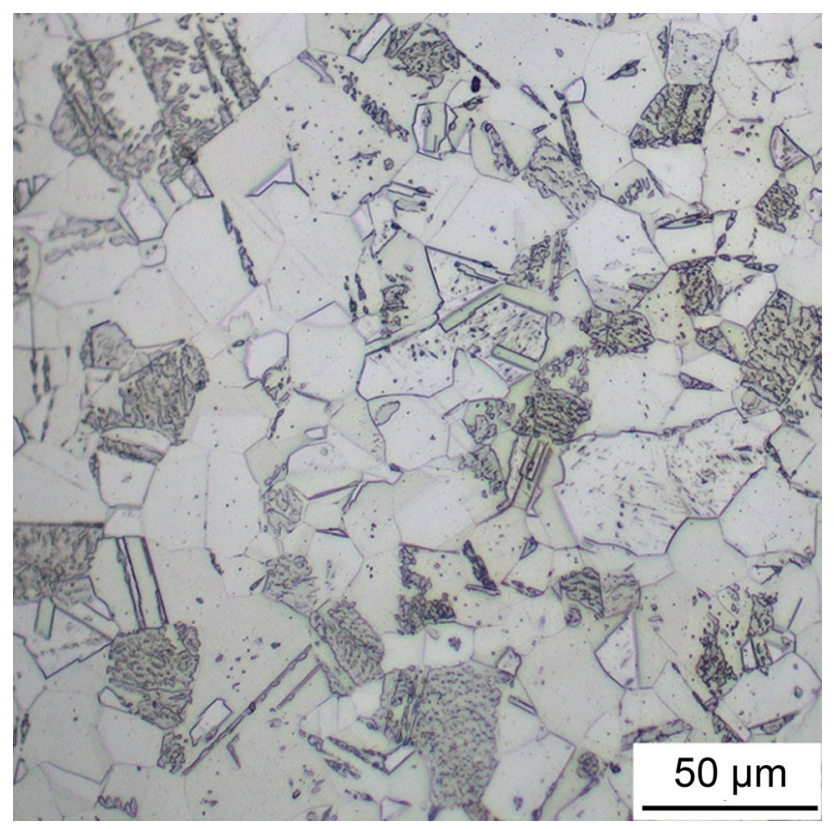

Fig. 2 Optical micrograph of SUS304 stainless steel

the chemical composition listed in Table 1, SFE used in this study was evaluated to be $\sim 16.2 \mathrm{~mJ} / \mathrm{m}^{2}$.

As for 304 stainless steel under uniaxial tension, two transformation mechanisms were proposed mainly according to the SFE $[4,15]$ : (1) stress-assisted martensite transformation, i.e., $\gamma \rightarrow \varepsilon \rightarrow \alpha^{\prime}$ and (2) strain-induced martensite transformation, i.e., $\gamma \rightarrow$ deformation twinning $\rightarrow \alpha^{\prime}$. It was reported that transformation dominates the deformation when SFE $<18 \mathrm{~mJ} / \mathrm{m}^{2}$, while deformation twinning occurs for $12 \mathrm{~mJ} / \mathrm{m}^{2}<\mathrm{SFE}<35 \mathrm{~mJ} / \mathrm{m}^{2}$ in metastable austenitic stainless steels [16].

In situ TEM observation on successive stages of transformation process during stretching at room temperature is shown in Fig. 3. Figure 3a shows the bright field image of the as-received state. A high density of dislocations was observed, but no $\varepsilon$ martensites were noted. While driving the tensile holder to extend the specimen to $30 \mu \mathrm{m}$, the $\varepsilon$ martensite platelets are preferentially induced from the sites of dislocation pile-ups in Fig. 3b, where the stress is concentrated. The $\varepsilon$ martensites were also found to nucleate from overlapping stacking faults (SF) which might be dissociated from perfect dislocation and grow by the movement of Shockley partial dislocation [17]. After the sample was stretched to $50 \mu \mathrm{m}$, as shown in Fig. 3c, it is very obvious that the $\varepsilon$ martensite platelet marked as $\mathrm{A}$ in Fig. $3 b$ disappears. The same phenomenon was observed when the sample was extended to $52 \mu \mathrm{m}$, the $\varepsilon$ martensite platelet marked as B in Fig. 3c also vanishes in Fig. 3d. It is a very interesting finding. Many previous literatures have suggested that $\varepsilon$ martensite is unstable and will totally transform to $\alpha^{\prime}$ martensite when plastic deformation occurs. This might be attributed to the lack of in situ observation and recording when deformation induced transformation happens $[6,12,15]$. Therefore, in the literature, no similar results have been reported on the disappearance of $\varepsilon$ martensite. Jiang et al. [18] performed in situ thermal experiments under TEM on deformed specimen from room temperature up to $600{ }^{\circ} \mathrm{C}$ in a Fe-30Mn-6Si shape memory alloy. They found that thick $\varepsilon$ martensite platelets are disintegrated layer by layer through the reverse motion and annihilation of partial dislocations, with the last induced $\varepsilon$ martensite being the first to disappear. Misra et al. [19, 20] indicated that heavily deformed strain-induced martensite transform back to austenite upon annealing in metastable austenitic stainless steel. Their experimental conditions were different from the current study. The disappearance may result from $\varepsilon$ martensite reversibly transforming to $\gamma$ austenite without heat treatment. Therefore, further investigations on reverse transformation mechanism of $\varepsilon$ martensite under different conditions are still needed.

When the specimens are stretched to $52 \mu \mathrm{m}$, the deformation twins unambiguously appear in the deformed austenite microstructure as shown in Fig. 3c, marked as areas $\mathrm{C}$ and D. Moreover, the deformation twins are nearly perpendicular to the $\varepsilon$ martensite platelets, which have rarely been reported in literature. These twins obviously grow along the vertical direction of $\varepsilon$ martensite platelets with increasing deformation indicated in Fig. 3d, marked as area E. In fcc (face-center-cubic) metals, SFs and deformation twins can be formed from the dissociation of a screw dislocation or a $60^{\circ}$ dislocation [15]. Deformation twins can be generated whether SFs are superposed on every second closest packed $\left(\begin{array}{lll}1 & 1 & 1\end{array}\right)_{\gamma}$ plane of the fcc crystal [3]. By the process of the $\left(\begin{array}{lll}1 & 1 & 1\end{array}\right)_{\gamma}$ plane shifting, it is indicated that $(10 \overline{1} 0)_{\varepsilon}$ planes should be perpendicular to (1 111 ) , planes [12]. Therefore, the deformation twins in the direction vertical to $\varepsilon$ martensite platelets are observed. As mentioned above, the SFE of SUS304 stainless steel in this study is within the range of $12-35 \mathrm{~mJ} / \mathrm{m}^{2}$, and the existence of the deformation twins is in agreement with previous reports $[4,16]$.

After extending the sample to $56 \mu \mathrm{m}, \alpha^{\prime}$ martensite starts to form, as shown in Fig. 3e. Further increased the displacement to $80 \mu \mathrm{m}$, more nucleating sites of $\alpha^{\prime}$ martensite are activated (Fig. 3f). From the corresponding selected-area-electron-diffraction (SAED) pattern (see the inserted), the composite diffraction pattern of austenite, twins, $\varepsilon$ martensite and $\alpha^{\prime}$ martensite could be identified. It is deduced that new nucleation sites of $\alpha^{\prime}$ martensite comes from deformation twins, $\varepsilon$ martensite platelets and their intersections. The present study demonstrates that the nucleation of martensite in SUS304 stainless steel can 



Fig. 3 In situ TEM observation on successive stages of transformation process during stretching: a As-received; b displacement of $30 \mu \mathrm{m}$; c displacement of $50 \mu \mathrm{m}$; d displacement of $52 \mu \mathrm{m}$; e displacement of $56 \mu \mathrm{m}$; $\mathbf{f}$ displacement of $80 \mu \mathrm{m}$

simultaneously occur at sites other than intersecting shear bands, which is usually referenced in previous literatures, and multiple mechanisms such as: $\gamma \rightarrow \varepsilon \rightarrow \gamma, \gamma \rightarrow \varepsilon$, $\gamma \rightarrow \alpha^{\prime}, \gamma \rightarrow \varepsilon \rightarrow \alpha^{\prime}, \gamma \rightarrow$ deformation twins $\rightarrow \alpha^{\prime}$ can coexist. Consequently, strain-induced transformation $\left(\gamma \rightarrow\right.$ deformation twins $\left.\rightarrow \alpha^{\prime}\right)$ and stress induced transformation $\left(\gamma \rightarrow \varepsilon \rightarrow \alpha^{\prime}\right)$ simultaneously occur, which also supports the previous findings $[6,15]$.

\section{Conclusions}

1. $\varepsilon$ Martensite platelets are preferentially induced from the sites of dislocation pile-ups. Some of the $\varepsilon$ martensite thin platelets disappear and reversibly transform back to $\gamma$ austenite with the increasing of tensile deformation without heat treatment, which is different from the previous findings that $\varepsilon$ martensite can entirely transform to $\alpha^{\prime}$ martensite.

2. Some of deformation twins appear and grow along the vertical direction of $\varepsilon$ martensite since $(10 \overline{1} 0)_{\varepsilon}$ planes are perpendicular to $\left(\begin{array}{lll}1 & 1 & 1\end{array}\right)$, planes.
3. Multiple transformation mechanisms via $\gamma \rightarrow \varepsilon \rightarrow \gamma$, $\gamma \rightarrow \varepsilon, \quad \gamma \rightarrow \alpha^{\prime}, \quad \gamma \rightarrow \varepsilon \rightarrow \alpha^{\prime}, \quad \gamma \rightarrow$ deformation twins $\rightarrow \alpha^{\prime}$ were directly observed. The strain-induced transformation and stress-induced transformation can co-exist.

Acknowledgments This work was financially supported by the National Natural Science Foundation of China (No. 51105248).

\section{References}

[1] W.D. Lee, C.F. Lin, Scr. Mater. 43, 777 (2010)

[2] A. Kundu, P.C. Chakraborti, J. Mater. Sci. 45, 5482 (2010)

[3] X.F. Li, J. Chen, L.Y. Ye, W. Ding, P.C. Song, Acta Metall. Sin. (Engl. Lett.) 26, 657 (2013)

[4] G.B. Olson, M. Cohen, Metall. Trans. A 7, 1897 (1976)

[5] G.B. Olson, M. Cohen, Metall. Trans. A 7, 1905 (1976)

[6] A. Das, S. Tarafder, Int. J. Plast 25, 2222 (2009)

[7] A. Das, Scr. Mater. 68, 514 (2013)

[8] L. Bracke, L. Kestens, J. Penning, Scr. Mater. 57, 385 (2007)

[9] J. Talonen, H. Hänninen, Acta Mater. 55, 6108 (2007)

[10] A.Y. Chen, H.H. Ruan, J. Wang, H.L. Chan, Q. Wang, Q. Li, J. Lu, Acta Mater. 59, 3697 (2011)

[11] H. Fujita, T. Katayama, Mater. Trans. 33, 242 (1992) 
[12] K.X. Tao, J.J. Wall, H.Q. Li, D.W. Brown, S.C. Vogel, H. Choo, J. Appl. Phys. 100, 123515 (2006)

[13] L. Zhang, B. An, T. Iijima, S. Fukuyama, K. Yokogawa, J. Appl. Phys. 110, 033540 (2011)

[14] R.E. Schramm, R.P. Reed, Metall. Trans. A 6, 1345 (1975)

[15] Y.F. Shen, X.X. Li, X. Sun, Y.D. Wang, L. Zuo, Mater. Sci. Eng. A 552, 514 (2012)

[16] S. Allain, J.P. Chateau, O. Bouaziz, Mater. Sci. Eng. A 387-389, 143 (2004)
[17] B.H. Jiang, T. Tadaki, H. Mori, T.Y. Hsu, Metall. Trans. 38, 1072 (1997)

[18] B.H. Jiang, T. Tadaki, H. Mori, T.Y. Hsu, Metall. Trans. 38, 1078 (1997)

[19] R.D.K. Misra, B. Ravi Kumar, M.C. Somani, L.P. Karjalainen, Scr. Mater. 59, 79 (2008)

[20] R.D.K. Misra, S. Nayak, P.K.C. Venkatasurya, V. Ramuni, M.C. Somani, L.P. Karjalainen, Metall. Mater. Trans. A 41, 2162 (2010) 